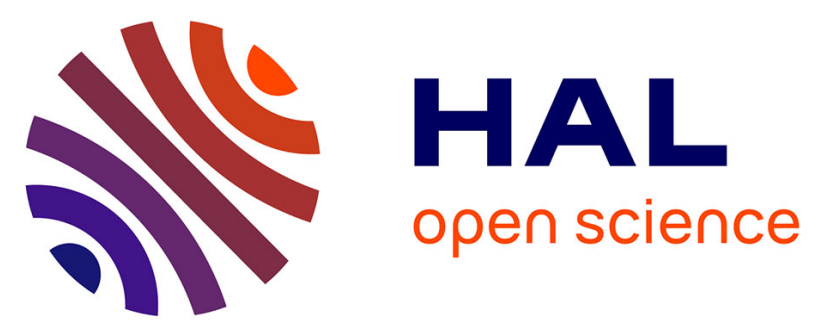

\title{
Ultrasound-detected connective tissue involvement in acute muscle injuries in elite athletes and return to play: The French National Institute of Sports (INSEP) study
}

Jérôme Renoux, Jean-Louis Brasseur, Mathilde Wagner, Alain Frey, Dominique Folinais, Christian Dibie, Djamila Maiza, Michel D. Crema

\section{To cite this version:}

Jérôme Renoux, Jean-Louis Brasseur, Mathilde Wagner, Alain Frey, Dominique Folinais, et al.. Ultrasound-detected connective tissue involvement in acute muscle injuries in elite athletes and return to play: The French National Institute of Sports (INSEP) study. Journal of Science and Medicine in Sport, 2019, 22, pp.641 - 646. 10.1016/j.jsams.2019.01.007 . hal-03487031

\section{HAL Id: hal-03487031 \\ https://hal.science/hal-03487031}

Submitted on 20 Dec 2021

HAL is a multi-disciplinary open access archive for the deposit and dissemination of scientific research documents, whether they are published or not. The documents may come from teaching and research institutions in France or abroad, or from public or private research centers.
L'archive ouverte pluridisciplinaire HAL, est destinée au dépôt et à la diffusion de documents scientifiques de niveau recherche, publiés ou non, émanant des établissements d'enseignement et de recherche français ou étrangers, des laboratoires publics ou privés.

\section{(ㄷ)(1) $\$$}

Distributed under a Creative Commons Attribution - NonCommerciall 4.0 International 
Ultrasound-detected connective tissue involvement in acute muscle injuries in elite athletes and return to play: the French National Institute of Sports (INSEP) study. Jérôme Renoux, $M D^{1,2}$; Jean-Louis Brasseur, $M D^{1,3}$; Mathilde Wagner, $M D^{3}$; Alain Frey, $M D^{4}$; Dominique Folinais, $M D^{5}$; Christian Dibie, $M D^{l}$; Djamila Maiza, $M D^{1}$; Michel D. Crema, $M D^{1,6,7}$.

1- Department of Radiology, French National Institute of Sports (INSEP), Paris, France

2- Department of Radiology, American Hospital of Paris, Neuilly-Sur-Seine, France

3- Department of Radiology, Pitié-Salpêtrière Hospital, APHP, UPMC Sorbonne University, Paris, France

4- Department of Sport Medicine, French National Institute of Sports (INSEP), Paris, France

5- Department of Radiology, Clinique Maussins-Nollet, Paris, France

6- Department of Radiology, Saint-Antoine Hospital, APHP, UPMC Sorbonne University, Paris, France

7- Department of Radiology, Quantitative Imaging Center, Boston University School of Medicine, Boston, MA, USA

\section{Corresponding Author:}

Michel D. Crema, MD

Department of Radiology, French National Institute of Sports (INSEP), 11 Avenue du Tremblay, 75012 Paris, France

Tel: +331744396

Email Address: michelcrema@gmail.com

Word count: Manuscript 2,740 words (excluding abstract and references), Abstract 247 words, Number of Tables - 2, Number of Figures -1 . 
1 Ultrasound-detected connective tissue involvement in acute muscle injuries in elite

2 athletes and return to play: the French National Institute of Sports (INSEP) study.

3

4

5

6

7

8

9

10

11

12

13

14

15

16

17

18

19 
Objective: Previous MRI studies showed that involvement of connective tissue in muscle injuries may prolong recovery times. The relevance of ultrasound assessment of connective tissue involvement as a prognostic factor is unknown. The aim was to test the hypothesis that ultrasound-detected connective tissue involvement in acute muscle injuries are related to longer recovery times.

Design: Cohort study.

Methods: Seventy consecutive elite athletes from the French National Institute of Sports (INSEP) sustaining an acute muscle injury showing positive findings on ultrasound at baseline were included. Ultrasound was systematically performed within 7 days after the injury for the assessment of severity (grades 1-4) and type of injury in regard to the absence (M injuries) or presence ( $\mathrm{C}$ injuries) of connective tissue involvement. The differences in the mean time needed to return to play (RTP) between the different grades and types of injury were assessed using multiple non-parametric tests.

Results: When considering the overall grades independently of the type of injury (M or C), an increase in the mean time needed to RTP was observed with the increase of grades ( $\mathrm{p}<0.0001)$. The same relationship was found when considering grades from $\mathrm{M}$ and $\mathrm{C}$ injuries separately, with higher grades of injuries exhibiting longer times needed to RTP $(\mathrm{p}<0.0001)$. Longer times needed to RTP were observed in athletes demonstrating C injuries in comparison to the ones exhibiting $\mathrm{M}$ injuries overall ( $\mathrm{p}=0.002)$.

Conclusion: Ultrasound-detected connective tissue involvement in acute muscle injuries are related to longer times needed to RTP, especially when disruption is detected.

42 Key words: muscle injuries; ultrasound, connective tissue injury; return to play 


\section{Introduction}

Acute muscle injuries are responsible for a large part of time lost to competition in elite athletes ${ }^{1-5}$. Current evidence regarding prediction of the time needed to return to play (RTP) based on imaging features is mainly related to hamstring research, with studies suggesting that a number of magnetic resonance imaging (MRI) findings are associated with the amount of time needed before RTP ${ }^{6-16}$. However, there are discrepancies in the literature regarding the predictive effect of some MRI features, with the use of MRI being contested by previous publications that could not reproduce the same results as previously published ${ }^{17-20}$.

Some studies shed light on the potential prognostic value of intramuscular connective tissue involvement in acute muscle injuries. Two studies showed evidence that MRI-detected intramuscular tendon involvement in hamstring injuries was associated with a delay in the time needed to RTP $^{9,10}$, and such feature was even included in a recent MRI classification system of muscle injuries, the British Athletics Muscle Injury system ${ }^{21}$. More recently, a prospective MRI study demonstrated that mainly full-thickness disruption and waviness of the intramuscular tendon in hamstring injuries was related to longer recovery times, but a limited prognostic value was found if taking into account any intramuscular tendon involvement ${ }^{12}$. Furthermore, another MRI study demonstrated that connective tissue involvement in calf muscle injuries can be used to estimate the time needed to RTP ${ }^{11}$.

Compared to MRI, ultrasound is relatively inexpensive and easily accessible, being widely used by many sports medicine teams in the diagnosis and follow-up of muscle injuries in elite athletes. Ultrasound provides a greater spatial resolution than MRI, allowing for detailed assessment of proximal and distal connective tissues in skeletal muscles, such as intramuscular tendon as well as intra- and peri-muscular aponeurosis. Compared to MRI, there is paucity of data regarding the clinical relevance of ultrasound findings in acute muscle 
67 injuries, with controversial results regarding their prognostic value ${ }^{8,22}$. Furthermore, no

previous ultrasound studies attempted to specifically identify involvement of muscular connective tissues in acute muscle injuries and its relationship with recovery times in athletes.

In order to demonstrate the prognostic value of ultrasound in assessing acute muscle injuries, we aimed to assess the relationships between ultrasound features of muscle injuries and the time needed to RTP in a sample of elite athletes followed at the (blinded), including ultrasound features of connective tissue involvement. We tested the hypothesis that muscle injuries exhibiting connective tissue involvement are associated with longer recovery times when compared to those without such involvement. Secondarily, we also tested the hypothesis that higher grades of ultrasound-detected injuries are related to longer recovery times.

\section{Methods}

Seventy consecutive elite athletes from several sports at (blinded) were retrospectively included in our study from 2011 to 2014 if they sustained an acute muscle injury showing positive findings on ultrasound at baseline. Ultrasound was systematically performed at the department of radiology of (blinded) within 7 days after the injury. Clinically, we defined acute muscle injuries as those where athletes complained of acute pain in a given muscle group, which immediately prevented the athlete from any activity in training or competition. Only muscle injuries from an indirect (intrinsic) mechanism were included in our study. Athletes were excluded in case of history of previous injuries involving the same muscle group affected by an acute injury. All athletes included had follow-up data regarding the length of time to RTP after muscle injuries. Ethical approval was obtained from the local Institutional Review Board which waived informed consent due to the retrospective nature of the study. 
91 All ultrasound examinations were performed by a single musculoskeletal radiologist with over

9210 years experience in sports medicine imaging. Ultrasound of the muscle group affected by

93 injury was performed using an Aplio XG (Canon Medical Systems, Europe B.V.), with a 8-12

$94 \mathrm{MHz}$ linear probe. The region of interest (representing the region of maximal pain and

tenderness as identified by the athlete) was systematically examined using transverse and

longitudinal scanning with the involved muscle group fully relaxed (at rest). The radiologist

considered only the primary acute injury, the one exhibiting the greater extent and severity for

each athlete. Bilateral examination was systematically performed for all muscle injuries

detected. The longitudinal and transverse images demonstrating the greater severity of injury were selected and saved in our Picture Archiving and Communication System (PACS). The specific muscle involved (related to the images saved) was also recorded. For the purpose of this study and to allow for a second independent assessment of ultrasound images, only images acquired with muscles at rest were included for the assessments.

All muscle injuries detected on ultrasound were graded according to the (blinded) classification system of acute muscle injuries ${ }^{23}$. This system takes into account two distinct types of intrinsic muscle injuries: "M" injuries, representing injury at the myo-connective classification system used in this study. For each injury type detected on ultrasound (M or C), represent a complete detachment or rupture at the myo-connective junction with major retraction, with no distinction between $\mathrm{M}$ and $\mathrm{C}$ injuries. Further, a second musculoskeletal 
radiologist with over 30 years experience in sports medicine independently reviewed all longitudinal and transverse ultrasound images saved initially in our PACS. The second reader was blinded to the initial report including the classification of each muscle injury, and also graded each injury according to the same scoring system.

All elite athletes included in our study followed the same treatment protocol at (blinded), adapted for each muscle group involved. The rehabilitation program was considered as successfully completed when sports-specific activities could be performed by the athlete without any restriction or pain. For each athlete, the time needed to RTP was noted by the sports medicine physician as the number of weeks between each acute muscle injury (day zero) and the return to unrestricted activity in training or competition. The supervising sports medicine physician gave the definite clearance for RTP.

We tested if there were differences in the time needed to RTP (in weeks) between the different grades of acute muscle injuries detected in our cohort using ultrasound. Further, we tested if there were differences in RTP between " $M$ " and " $C$ " injuries detected, including data on the whole sample of athletes, on the most common sport only, and on the most common muscle group affected only. The non-parametric Mann-Whitney and Kruskal-Wallis tests were used to assess the differences in RTP between the different groups and grades of muscle injuries. The Bonferroni correction method was applied when multiple comparisons were performed. The hypothesis log-rank test and Kaplan-Meier plots were used to compare the means of time needed to RTP in the different groups and grades of injuries. The inter-reader reliability of ultrasound assessments was evaluated using kappa statistics. Statistical significance was set at 0.05 . All analyses were performed using the SAS software version 9.4 (SAS Institute, Cary NC). 


\section{Results}

141 Seventy elite athletes sustaining an acute muscle injury were included, one injury per athlete.

142 The mean age was 27.8 years $( \pm 6.1$; range $22-55)$ and $65.7 \%$ of athletes were male $(\mathrm{N}=46)$.

143 The majority of muscle injuries affected track and field athletes $(\mathrm{N}=25,35.7 \%)$ followed by

144 rugby players $(\mathrm{N}=18,25.7 \%)$, with a variety of sports related to the remaining athletes

145 including football $(\mathrm{N}=5)$, judo $(\mathrm{N}=5)$, basketball, pentathlon, and fencing $(\mathrm{N}=3$ each), boxing,

146 tennis, and water polo ( $\mathrm{N}=2$ each), field hockey and jiu-jitsu $(\mathrm{N}=1$ each). From 70 injuries

147 assessed on ultrasound, there were 31 hamstring injuries (44.3\%), 11 calf injuries (15.7\%), 10

148 quadriceps injuries (14.3\%), 6 adductors injuries (8.6\%), and 1 gluteus maximus injury

149 (1.4\%), for a total of 59 injuries affecting muscles from the lower limbs (84.3\%). Muscles

150 from the arm $(\mathrm{N}=5,7.1 \%)$ and the abdominal wall $(\mathrm{N}=4,5.7 \%)$ were the most commonly

151 affected by injuries outside the lower limbs.

152 Regarding the classification of muscle injuries on ultrasound, 52 were classified as type M

153 injuries (74.3\%) and 18 as type $\mathrm{C}$ injuries (25.7\%). There were no differences in age between

154 the athletes exhibiting $M$ injuries (30.7 years \pm 6.5$)$ and those exhibiting $\mathrm{C}$ injuries (30.8 years

$155 \pm 4.5)$.However, a difference was observed in terms of gender, with $61.5 \%(\mathrm{~N}=31)$ males in

156 the "M injuries" group and 77.8\% (n=14) males in the "C injuries" group. Twenty-four

157 injuries were classified as grade $1(34.3 \%), 34$ as grade $2(48.6 \%)$, and 12 as grade $3(17.1 \%)$.

158 No grade 4 injuries were found in our cohort. From 52 type $\mathrm{M}$ injuries, 24 were grade $1 \mathrm{M}$

159 (34.3\%), 22 were grade $2 \mathrm{M}(31.4 \%)$, and 6 were grade $3 \mathrm{M}(8.6 \%)$. From 18 type $\mathrm{C}$ injuries,

16012 were grade $2 \mathrm{C}(17.1 \%)$ and 6 were grade $3 \mathrm{C}(8.6 \%)$. No grade $1 \mathrm{C}$ injuries were found. The

161 inter-reader reliability (kappa) for each specific injury grade was 0.45 ( $\mathrm{p}<0.0001)$, and for the

162 type of injury (M or C) was $0.65(\mathrm{p}<0.0001)$.

163 When considering the overall grades (1 to 3 ) independently of the type of injury (M or C), an

164 increase in the mean time needed to RTP was observed with the increase of grades $(\mathrm{p}<0.0001$ 
for all comparisons performed; Table 2; Appendix 1). The same relationship was found when considering grades from $\mathrm{M}$ and $\mathrm{C}$ injuries separately, with higher grades of injuries exhibiting longer times needed to RTP ( $\mathrm{p}<0.0001$ for all comparisons performed; Table 2; Appendix 1). Longer times needed to RTP were observed in athletes demonstrating C injuries in comparison to the ones exhibiting $\mathrm{M}$ injuries (all $\mathrm{C}$ injuries vs. all $\mathrm{M}$ injuries; $\mathrm{p}=0.002$; Table 2; Appendix 1). Although we observed a higher mean time needed to RTP for each grade of $\mathrm{C}$ injuries when compared to each grade of $\mathrm{M}$ injuries ( $2 \mathrm{C}$ vs. $2 \mathrm{M} ; 3 \mathrm{C}$ vs. $3 \mathrm{M}$ ), these differences were not statistically significant, and the standard deviation values obtained indicate overlap (Table 2).

Considering athletes from track and field only, the most common sport in our sample $(\mathrm{N}=25$, $35.7 \%$ ), we found that longer times needed to RTP were observed in athletes exhibiting C injuries (7.8 mean weeks $\pm 3.8 ; 95 \% \mathrm{CI} 5.6,10.0)$ compared to those exhibiting M injuries (4.8 mean weeks $\pm 2.6 ; 95 \%$ CI $3.5,6.1) ; \mathrm{p}=0.03$. For the other sports related to the remaining athletes included, the low number of athletes in each sport and consequently the lack of statistical power do not allow for additional analyses regarding the relationship between the types of injuries and recovery times.

Considering athletes exhibiting hamstring injuries only, the most common muscle group affected by injury in our sample $(\mathrm{N}=31,44.3 \%)$, we found that longer times needed to RTP were observed in athletes exhibiting $\mathrm{C}$ injuries (7.9 mean weeks $\pm 4.9 ; 95 \% \mathrm{CI} 5.3,10.5$ ) compared to those exhibiting $\mathrm{M}$ injuries $(4.1$ mean weeks $\pm 2.3 ; 95 \% \mathrm{CI} 3.1,5.1) ; \mathrm{p}<0.01$. For the other muscle groups affected, the low number of athletes and consequently the lack of statistical power do not allow for additional analyses regarding the relationship between the types of injuries and recovery times. 


\section{Discussion}

In this sample of elite athletes sustaining an acute muscle injury assessed on ultrasound, we found that higher grades of injury exhibited longer recovery times when considering the general grades (1 to 3) as well as when comparing different grades of the same type of injury (M or C). Furthermore, considering only the type of injury, we found that recovery times were longer for athletes exhibiting $\mathrm{C}$ injuries in comparison with those having $\mathrm{M}$ injuries in general. However, when specifically comparing the same grades from different types of injury (2M vs. $2 \mathrm{C}$ and $3 \mathrm{M}$ vs. $3 \mathrm{C}$ ), no significant differences were found in the time needed to RTP. Finally, we report a moderate agreement between both radiologists when considering each specific grade from the classification system of muscle injuries assessed on ultrasound. However, a substantial agreement between radiologists was found when considering the type of muscle injury ( $\mathrm{M}$ or $\mathrm{C})$.

Previous MRI studies highlighted the potential clinical relevance of muscle injuries affecting connective tissues such as the intramuscular tendon involvement in hamstring injuries ${ }^{9,10}$ and rectus femoris injuries ${ }^{15}$, as well as connective tissue involvement in calf injuries (tendon, aponeurosis, and epimysium) ${ }^{11}$. These studies showed that injuries affecting connective tissues demonstrated longer recovery times than those without such involvement, especially in cases of disrupted and/or retracted connective structures. A recent prospective MRI study evaluated the presence of intramuscular tendon involvement in hamstring injuries and the relationship with the time needed to RTP ${ }^{12}$. The authors found that hamstring injuries exhibiting full-thickness disruption of the intramuscular tendon and the presence of a "waviness" pattern of the intramuscular tendon were associated with slightly longer recovery times compared with injuries without intramuscular tendon involvement. However, the authors found that partial-thickness disruption of the intramuscular tendon did not substantially increase the time needed to RTP. Because the slight prolonged RTP and 
214 considerable overlap between groups compared, the authors concluded that the clinical

215 relevance of intramuscular tendon involvement was limited in regard to prognosis ${ }^{12}$.

216 Ultrasound allows visualization of muscular architecture at in-plane resolutions of under

$217200 \mu \mathrm{m}$ and section thickness of $0.5-1.0 \mathrm{~mm}$, which exceeds current MRI ${ }^{24}$. Compared to

218 MRI, it also offers a number of distinct advantages: it is fast, relatively cheap, easier for

219 patients, and allows dynamic evaluations. Furthermore, ultrasound can demonstrate the

220 muscle structure and other relevant anatomy surrounding an injury that can often be obscured

221 by edema on MRI ${ }^{8}$, including high-resolution assessment of intra- and peri-muscular

222 connective tissues, intramuscular tendon, and intramuscular aponeurosis. Previous studies

223 used ultrasound to evaluate features of acute muscle injuries and their relationship with RTP

$224 \quad 8,22$. A longitudinal study of acute hamstring injuries comparing ultrasound and MRI features

225 evaluated the correlations between imaging features and recovery times. The authors found

226 the cross-sectional area of the injury and the presence of an intramuscular hematoma depicted

227 on ultrasound were positively correlated to the time needed to RTP ${ }^{8}$. Another study

228 evaluating the prognostic value of ultrasound features of hamstring injuries in soccer players

229 showed no significant differences in the time needed to RTP between athletes with and

230 without ultrasound abnormalities ${ }^{22}$. Further, the same study found no correlation between the

231 length of injuries and the time needed to RTP.

232 None of the previous ultrasound studies specifically assessed connective tissue involvement in

233 muscle injuries and its relationship with RTP. To the best of our knowledge, our study is the

234 first to take into account ultrasound features of connective tissue involvement in muscle

235 injuries as prognostic factors. The classification system used in our study ${ }^{23}$ distinguishes

236 injuries exhibiting ultrasound involvement of intra- and perimuscular connective tissues $(\mathrm{C}$

237 injuries) from those without such involvement ( $\mathrm{M}$ injuries). Considering all grades of injuries

238 detected in our sample, we found that athletes with $\mathrm{C}$ injuries exhibited longer (mean) 
recovery times than those with $\mathrm{M}$ injuries (3.7 weeks mean time longer for $\mathrm{C}$ injuries). This

240 supports the existing evidence from previous MRI studies ${ }^{9-12,15}$, reinforcing the idea that

241 connective tissue involvement in muscle injuries has some prognostic value. Longer recovery

242 times related to $\mathrm{C}$ injuries were also demonstrated when considering athletes from track and

243 field only (most common sport in our sample), as well as when considering athletes exhibiting

244 hamstring injuries only (most common muscle group affected in our sample), with the global

245 mean recovery times for different grades of $\mathrm{C}$ injuries being comparable to the ones from a

246 previous study including only track and field athletes with hamstring injuries ${ }^{10}$. We also

247 demonstrated that injuries with disruption of the involved connective tissue (grade 3C; Figure

248 1) exhibited even longer recovery times when compared with those without disruption of the

249 involved connective tissue (grade 2C) (6.4 weeks mean time longer for 3C injuries). This also

250 supports the results from previous MRI studies, which demonstrated that injuries exhibiting

251 disruption and/ or retraction of the involved connective tissue were related to longer mean

252 times needed to RTP ${ }^{10-12}$. When directly comparing the same grades of different types of

253 injuries, we found a slight increase in the mean time needed to RTP for C injuries (1.3 weeks

254 mean time difference between $2 \mathrm{C}$ and $2 \mathrm{M}$; 1.6 weeks mean time difference between $3 \mathrm{C}$ and

$2553 \mathrm{M})$. However, the standard deviation values found indicate overlap between these groups,

256 and such differences are difficult to interpret. Higher grades of ultrasound-detected injuries

257 were related to longer recovery times considering M injuries only, as well as the overall

258 grades regardless of the type of injuries.

259 Connective tissue involvement in muscle injuries, mainly connective tissue disruption, seems

260 to be the one morphological feature exhibiting some clinical relevance in terms of recovery

261 times of athletes and our study demonstrated that ultrasound assessment of muscle injuries is

262 capable of depicting such involvements, which lead to longer recovery times in our sample.

263 Injuries affecting muscular connective tissues such as the intramuscular tendon, the 
264 perimuscular aponeurosis, or the intramuscular aponeurosis seem to lead to a dysfunction in

265 its biomechanics, as such tissues act not only as an anatomical support to the muscular tissue

266 but also in transmitting both tensile and shear loads generated by muscles, transmitting force

267 from a segment to another ${ }^{25,26}$. Thus, alterations in the structure of such tissues (mainly

268 disruption) would impair these important biomechanical functions, which could explain why

269 connective tissue involvement in muscle injuries is related with longer recovery times.

270 Compared to MRI, ultrasound may be easily implemented in sports medicine facilities, even

271 within the field, and be used to evaluate connective tissue integrity in acute muscle injuries,

272 providing thus some prognostic input to athletes and physicians.

273 Our study has some limitations. As we included only elite athletes, the results of our study

274 may not reflect the general population. Also, the supervising sports medicine physicians

275 responsible for the definite clearance for RTP were not blinded to the results from the initial

276 ultrasound performed. This included knowledge about the presence or absence of connective

277 tissue involvement. However, at the time of the inclusion period (2011 to 2014), there was no

278 strong evidence that general connective tissue involvement in different muscle groups was

279 associated with longer recovery times in athletes, with only one publication available

280 assessing the intramuscular tendon involvement in the hamstring ${ }^{9}$. The time needed to RTP

281 could also be influenced by the athlete's motivation to RTP and pressure to compete exerted

282 by the teams. Further, we acknowledge that the time needed to RTP may vary during

283 preseason, season, and postseason. Although the initial treatment protocol for muscle injuries

284 was similar among the athletes included, the rehabilitation program was further adapted for

285 each muscle group affected and sport-specific activities were implemented during the

286 program, which might have influenced our results. The inter-reader reliability assessment was

287 not performed following a second and independent real repeated examination but rather a re-

288 reading of the images documented in the first place. Finally, we included injuries from 
different muscle groups from elite athletes practicing various sports, and since each muscle 290 group has different anatomy and function related to sport-specific activities, this might have 291 played a role in the results.

\section{Conclusion}

294 Ultrasound-detected connective tissue involvement in acute muscle injuries of elite athletes 295 are related to longer times needed to RTP, especially when a disrupted connective tissue 296 (intramuscular tendon or aponeurosis) is detected, which is in accordance to previous MRI 297 studies. Radiologists performing ultrasound in acute muscle injuries should drive their attention to the connective tissue integrity near areas of injury, which may potentially estimate the duration of rehabilitation in elite athletes. Further prospective studies applying ultrasound in injuries of specific muscle groups and specific sports are necessary to confirm the prognostic value of ultrasound-detected connective tissue involvement.

302

303

304

305

306

307

308

309

310 


\section{Practical Implications}

- Overall, muscle injuries exhibiting connective tissue involvement depicted using ultrasound (C injuries) are related to longer times needed to RTP in comparison with injuries without such involvement ( $M$ injuries).

- Considering only muscle injuries with connective tissue involvement seen on ultrasound (C injuries), those exhibiting discontinuity of the involved connective tissue are related to longer recovery times than those without discontinuity.

- Our study supports the existing limited evidence that connective tissue involvement in muscle injuries are related to longer recovery times, and such involvement might be detected using ultrasound, which is relatively inexpensive and easily accessible compared to MRI.

Acknowledgements: We thank all staff from the sports medicine and radiology departments at (blinded) for their support and help.

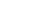




\section{References}

333 1. Ekstrand J, Hagglund M, Walden M. Epidemiology of muscle injuries in professional 334 football (soccer). Am J Sports Med 2011; 39(6):1226-1232.

335 2. Elliott MC, Zarins B, Powell JW, et al. Hamstring muscle strains in professional 336 football players: a 10-year review. Am J Sports Med 2011; 39(4):843-850.

337 3. Engebretsen L, Soligard T, Steffen K, et al. Sports injuries and illnesses during the 338 London Summer Olympic Games 2012. Br J Sports Med 2013; 47(7):407-414.

339 4. Soligard T, Steffen K, Palmer D, et al. Sports injury and illness incidence in the Rio de 340 Janeiro 2016 Olympic Summer Games: A prospective study of 11274 athletes from 207 341 countries. Br J Sports Med 2017; 51(17):1265-1271.

342 5. Feddermann-Demont N, Junge A, Edouard P, et al. Injuries in 13 international 343 Athletics championships between 2007-2012. Br J Sports Med 2014; 48(7):513-522.

344 6. Ekstrand J, Healy JC, Walden M, et al. Hamstring muscle injuries in professional 345 football: the correlation of MRI findings with return to play. Br J Sports Med 2012; $346 \quad 46(2): 112-117$.

347 7. Askling CM, Tengvar M, Saartok T, et al. Acute first-time hamstring strains during 348 high-speed running: a longitudinal study including clinical and magnetic resonance imaging 349 findings. Am J Sports Med 2007; 35(2):197-206.

350 8. Connell DA, Schneider-Kolsky ME, Hoving JL, et al. Longitudinal study comparing 351 sonographic and MRI assessments of acute and healing hamstring injuries. AJR Am J 352 Roentgenol 2004; 183(4):975-984.

353 9. Comin J, Malliaras P, Baquie P, et al. Return to competitive play after hamstring 354 injuries involving disruption of the central tendon. Am J Sports Med 2013; 41(1):111-115.

355 10. Pollock N, Patel A, Chakraverty J, et al. Time to return to full training is delayed and 356 recurrence rate is higher in intratendinous ('c') acute hamstring injury in elite track and field 
athletes: clinical application of the British Athletics Muscle Injury Classification. Br J Sports Med 2016; 50(5):305-310.

11. Prakash A, Entwisle T, Schneider M, et al. Connective tissue injury in calf muscle tears and return to play: MRI correlation. Br J Sports Med 2018; 52(14):929-933.

12. van der Made AD, Almusa E, Whiteley R, et al. Intramuscular tendon involvement on MRI has limited value for predicting time to return to play following acute hamstring injury. Br J Sports Med 2018; 52(2):83-88.

13. Slavotinek JP, Verrall GM, Fon GT. Hamstring injury in athletes: using MR imaging measurements to compare extent of muscle injury with amount of time lost from competition. AJR Am J Roentgenol 2002; 179(6):1621-1628.

14. Gibbs NJ, Cross TM, Cameron M, et al. The accuracy of MRI in predicting recovery and recurrence of acute grade one hamstring muscle strains within the same season in Australian Rules football players. J Sci Med Sport 2004; 7(2):248-258.

15. Cross TM, Gibbs N, Houang MT, et al. Acute quadriceps muscle strains: magnetic resonance imaging features and prognosis. Am J Sports Med 2004; 32(3):710-719.

16. Cohen SB, Towers JD, Zoga A, et al. Hamstring injuries in professional football players: magnetic resonance imaging correlation with return to play. Sports Health 2011; $3(5): 423-430$.

17. Crema MD, Godoy IRB, Abdalla RJ, et al. Hamstring Injuries in Professional Soccer Players: Extent of MRI-Detected Edema and the Time to Return to Play. Sports Health 2018; 10(1):75-79.

18. Moen MH, Reurink G, Weir A, et al, Goudswaard GJ. Predicting return to play after hamstring injuries. Br J Sports Med 2014; 48(18):1358-1363. 
19. Reurink G, Brilman EG, de Vos RJ, et al. Magnetic resonance imaging in acute hamstring injury: can we provide a return to play prognosis? Sports Med 2015; 45(1):133146.

20. Jacobsen P, Witvrouw E, Muxart P, et al. A combination of initial and follow-up physiotherapist examination predicts physician-determined time to return to play after hamstring injury, with no added value of MRI. Br J Sports Med 2016; 50(7):431-439.

21. Pollock N, James SL, Lee JC, et al. British athletics muscle injury classification: a new grading system. Br J Sports Med 2014; 48(18):1347-1351.

22. Petersen J, Thorborg K, Nielsen MB, et al. The diagnostic and prognostic value of ultrasonography in soccer players with acute hamstring injuries. Am J Sports Med 2014; 42(2):399-404.

23. Brasseur JL, Renoux J. Echographie du muscle. Paris, France: Sauramps Medical 2016:130-166.

24. Van Holsbeeck M, Introcasco J. Sonography of Muscle. In:Musculoskeletal Ultrasound. St Louis, MI. Mosby 2001.

25. Stecco $\mathrm{C}$, Pavan $\mathrm{P}$, Pachera $\mathrm{P}$, et al. Investigation of the mechanical properties of the human crural fascia and their possible clinical implications. Surg Radiol Anat 2014;36(1):2532.

26. Pavan PG, Stecco A, Stern R, et al. Painful connections: densification versus fibrosis of fascia. Curr Pain Headache Rep 2014;18(8):441. 
Table 1. The (blinded) ultrasound classification of muscle injuries including severity (grades

1-4) and type (M or C) of injuries.

\begin{tabular}{|c|c|c|}
\hline Type of Injury & $\begin{array}{l}\text { M injuries } \\
\text { (normal ultrasound } \\
\text { appearance of the adjacent } \\
\text { connective tissues) }\end{array}$ & $\begin{array}{l}\text { C injuries } \\
\text { (abnormal ultrasound } \\
\text { appearance of the adjacent } \\
\text { connective tissues) }\end{array}$ \\
\hline Grades & & \\
\hline 1 & $\begin{array}{l}\text { Intramuscular ill-defined } \\
\text { areas of increased } \\
\text { echogenicity without } \\
\text { architectural distortion at the } \\
\text { myo-connective junction }\end{array}$ & $\begin{array}{l}\text { Connective tissue exhibiting } \\
\text { thickening and ill-defined } \\
\text { contours without } \\
\text { architectural distortion at the } \\
\text { myo-connective junction. No } \\
\text { connective tissue } \\
\text { discontinuity. }\end{array}$ \\
\hline 2 & $\begin{array}{l}\text { Ill-defined areas of increased } \\
\text { echogenicity with } \\
\text { architectural distortion at the } \\
\text { myo-connective junction, no } \\
\text { visible detachment of muscle } \\
\text { fibers, no adjacent hematoma }\end{array}$ & $\begin{array}{l}\text { Connective tissue exhibiting } \\
\text { thickening and ill-defined } \\
\text { contours with architectural } \\
\text { distortion at the myo- } \\
\text { connective junction. No } \\
\text { connective tissue } \\
\text { discontinuity. }\end{array}$ \\
\hline 3 & $\begin{array}{l}\text { Partial detachment of muscle } \\
\text { fibers at the myo-connective } \\
\text { junction with adjacent } \\
\text { hematoma }\end{array}$ & $\begin{array}{l}\text { Partially ruptured connective } \\
\text { tissue with or without } \\
\text { adjacent hematoma }\end{array}$ \\
\hline 4 & \multicolumn{2}{|c|}{$\begin{array}{l}\text { Complete detachment or rupture at the myo-connective } \\
\text { junction with major retraction }\end{array}$} \\
\hline
\end{tabular}


411 Table 2. Differences in the mean time needed to return to play (RTP) when considering the

412 overall grades (1 to 3 ) and each grade for each type of injury ( $\mathrm{M}$ or $\mathrm{C}$ ) detected on ultrasound

$413 \quad(\mathrm{p}<0.0001$ for all statistical comparisons performed for the overall grades and for grades

414 within each type of injury). Differences in RTP between all M injuries vs. all C injuries were

415 statistically significant $(\mathrm{p}=0.002)$.

\begin{tabular}{|c|c|c|c|}
\hline \multirow[t]{2}{*}{ Overall grades } & RTP (weeks) & Min-Max & $95 \% \mathrm{CI}$ \\
\hline & \multicolumn{3}{|l|}{ Mean \pm SD } \\
\hline $1(n=24)$ & $2.2 \pm 1.1$ & $0-4$ & $1.7,2.6$ \\
\hline $2(n=34)$ & $4.6 \pm 1.9$ & $2-9$ & $3.9,5.2$ \\
\hline $3(n=12)$ & $11.1 \pm 3.6$ & $6-17$ & $9.1,13.1$ \\
\hline M Injuries & RTP (weeks) & Min-Max & $95 \% \mathrm{CI}$ \\
\hline Grades & Mean \pm SD & & \\
\hline $1(n=24)$ & $2.2 \pm 1.1$ & $0-4$ & $1.7,2.6$ \\
\hline $2(n=22)$ & $4.1 \pm 1.6$ & $2-8$ & $3.4,4.8$ \\
\hline $3(n=6)$ & $10.2 \pm 3.8$ & $6.7-17$ & $7.2,13.2$ \\
\hline All M injuries $(n=52)$ & $3.9 \pm 1.4$ & $0-17$ & $3.5,4.3$ \\
\hline C Injuries & Mean \pm SD & Min-Max & \\
\hline \multicolumn{4}{|l|}{ Grade } \\
\hline $2(n=12)$ & $5.4 \pm 2.3$ & $3-9$ & $4.1,6.7$ \\
\hline $3(n=6)$ & $11.8 \pm 3.6$ & $6-16$ & $8.9,14.7$ \\
\hline All C injuries $(n=18)$ & $7.6 \pm 2.9$ & $3-16$ & $6.3,8.9$ \\
\hline
\end{tabular}




\section{Figure 1' Legend}

418 A. Ultrasound-detected grade $3 \mathrm{C}$ injury at the proximal myo-tendinous junction of the long 419 head of the biceps femoris muscle in a 21-year-old male sprinter. Partial disruption of the 420 intramuscular tendon is depicted (arrows), exhibiting ill-defined margins, hypoechogenicity

421 and focal central thinning consistent with focal partial discontinuity. B. A normal ultrasound 422 appearance of the tendon in another elite athlete for comparison, exhibiting well-defined 423 margins and high echogenicity, with preserved thickness at the proximal myotendinous 424 junction (arrows). A and B: transverse views.

\section{Appendix 1' Legend}

428 Corresponding curve plots for the differences in the mean time needed to RTP when considering the overall grades independently of the type of injury $(\mathrm{p}<0.0001$ for all comparisons performed), when considering the grades for $\mathrm{M}$ or $\mathrm{C}$ injuries specifically

432 injuries $(\mathrm{p}=0.002)$. 
(2)

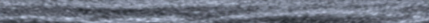
Em W:

(a)

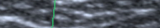

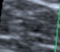

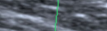
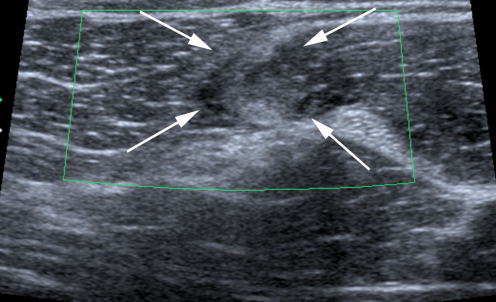


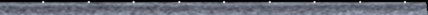

W

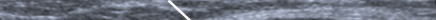

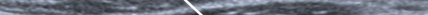

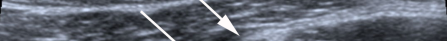

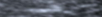

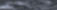

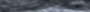

10

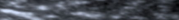

